\section{Testemunhos sobre transgeneridade e a constituição de novas subjetivações em Quem Sou Eu?}

Diego Gouveia Moreira

\section{Resumo:}

É da natureza do jornalismo o uso de testemunhos na construção de reportagens. Esse caráter testemunhal vem da observação do profissional, dos depoimentos das fontes e do consumidor da notícia. Com o avanço dos movimentos sociais LGBTQIAP+ e a necessidade de as marcas investirem em responsabilidade social, algumas iniciativas do jornalismo televisivo mudaram o tratamento dado à transgeneridade. Em 2017, a Rede Globo lançou, no Fantástico, a série Quem Sou Eu?, que conta histórias de pessoas transgêneras em fases distintas, ressaltando a diferença entre identidade de gênero e orientação sexual. O objetivo deste artigo é compreender como os testemunhos nas reportagens contribuem para novas subjetivações sobre a temática. Para isso, além de levantamento bibliográfico sobre jornalismo, testemunho, gênero e sexualidade, foram analisadas as quatro reportagens e também o site criado pela emissora para o especial. Por fim, constata-se que a série amplia as compreensões sobre transgeneridade, embora esteja ainda circunscrita a um entendimento de gênero como masculino e feminino.

Palavras-chave: Telejornalismo. Transgeneridade. Subjetivação.

Testimonies about transgenderity and constitution of new subjectivations in Quem Sou Eu?

\begin{abstract}
:
It is the nature of journalism to use testimonies in the construction of TV featuress. That witness character comes from professional observation, testimonies from sources and the consumer of the news. With the advancement of LGBTQIAP+ social movements and the need for brands to invest in social responsibility, some television journalism initiatives have changed the treatment of transgenderity. In 2017, Rede Globo launched, in Fantástico, a series Quem Sou Eu?, that shows stories of transgender people in different phases, highlighting the difference between gender identity and sexual orientation. The purpose of this article is to understand how the testimonies in the TV featuress contribute to new subjectivations on the subject. For that, in addition to a bibliographic survey on journalism, testimony, gender and sexuality, the four features and the website created to expand discussion were analyzed. Finally, it appears that the series expands the understanding of transgenderity, although it is still limited to an male and female gender understanding.
\end{abstract}

Keywords: Telejournalism. Transgeneration. Subjectivation.
Recebido em: 13.06 .20

Aprovado em: 05.02.21

Diego Gouveia Moreira

Professor do Núcleo de

Design e Comunicação

do Centro Acadêmico do

Agreste da Universidade

Federal de Pernambuco.

E-mail: dgmgouveia@ gmail.com 
testemunho da mídia, de acordo com Frosh e Pinchevski (2009), é aquele realizado na, pela e por meio da mídia. Assim, os autores consideram que a produção da notícia compreende o caráter testemunhal a partir de três dimensões principais: a do repórter diante do fato a ser narrado, a das fontes que contam sua versão da história e a dos consumidores, que testemunham o conteúdo veiculado.

Os autores Frosh e Pinchevski (2018) consideram que esse olhar sobre o caráter testemunhal da mídia contribui para novas problematizações no campo visto que muitas estão centradas nos estudos sobre representação e mediação. Para este artigo, essa compreensão interessa quando volta a atenção sobre o testemunho para a formação de novas subjetivações.

Esse processo de produção de subjetividades é feito, também, a partir da mídia, que opera como um dispositivo responsável pela produção de modos de ser, ver, viver. Aproximando do objeto de análise desta pesquisa, observa-se que, por muitos anos, às pessoas transexuais, era relegado o espaço nas notícias policiais ou sobre excentricidades (HARTMANN, 2014; OLIVEIRA, 2018). Os programas policialescos, ao falarem sobre transexuais/travestis em situação de conflito com a lei, tematizam o assunto de forma agressiva e empregam operadores linguísticos e argumentativos pejorativos para enunciar as entrevistadas. Sobressai-se, desse modo, o aspecto desumanizador, que zomba das pessoas transexuais. Não se notava na TV, meio de comunicação com presença em $98 \%$ dos lares brasileiros (MÍDIA DADOS, 2018), um avanço no debate social em relação ao assunto. Entre outras, duas condições favoreceram uma transformação no tratamento dado pela TV à questão. A ampliação e a maior visibilidade de movimentos sociais de Lésbicas, Gays, Bissexuais, Travestis, Transexuais, Queers, Questionando, Intersex, Assexuais, Arromânticas, Agêneras, Pansexuais, Polissexuais e mais (LGBTQIAP+) e a meta de emissoras comerciais em serem vistas como socialmente responsáveis a partir de uma estratégia de marca para o mercado.

Os grandes grupos econômicos brasileiros viram, na redemocratização, um cenário propício para legitimar o processo de globalização. Com as leis de mercado acima de qualquer outra, a ideologia do progresso e a ênfase na produtividade e nos bens de consumo ganharam mais espaço. O Grupo Globo integra esse grupo de empresas.

No plano ideológico, no entanto, essa vitória política e econômica passou a ser contestada por grupos sociais descontentes com os posicionamentos das marcas. De olho nesse movimento, as empresas passaram a usar a responsabilidade social (quando as empresas investem em discursos por uma sociedade melhor) como resposta a "um crescente mau-humor de setores organizados da sociedade para com as grandes corporações (ROCHA, 2010, p. 194).

Assim, há, de 2013 até 2020, um movimento para abordar gênero e sexualidade em produtos da Rede Globo a partir de outras perspectivas, incluindo a educação para o tema e apontamentos sobre direitos LGBTQIAP+. Houve especiais sobre transexualidade nos jornalísticos da Rede Globo: Profissão Repórter, em 2014, 2016 e 2019; Globo Repórter, em 2016; Fantástico, com o quadro Quem Sou Eu?, em 2017, além de produtos ficcionais, especialmente, a partir de Salve Jorge que mudou a forma de discutir transgeneridade nas telenovelas. Em 2017, inclusive, a emissora, com A Força do Querer, discutiu o tema com o personagem Ivana, que se reconhece como homem transexual ao longo da trama e passa a se chamar Ivan.

A série Quem Sou Eu? foi escolhida para análise por despontar como o principal produto sobre o tema na emissora ao vencer o prêmio Vladimir Herzog de Anistia e Direitos Humanos de 2017. O artigo problematiza, então, como os testemunhos nas reportagens contribuem para novas subjetivações sobre a temática. Assim, os aspectos testemunhais serão avaliados por meio de três dimensões: a 
do repórter diante do fato a ser narrado, a das fontes e a dos consumidores. Para isso, foram mapeadas as estratégias discursivas presentes no discurso da emissora e das fontes para promover novas subjetivações em torno da temática. Além de um estudo sobre telejornalismo, gênero e sexualidade, as reportagens do Fantástico foram acompanhadas em diários de observação. A pesquisa realizada compreende-se qualitativa, uma vez que as quatro reportagens e o site foram analisados a partir dos dados coletados e descritos nos diários de observação. Possui natureza descritiva, uma vez que estes correspondem a diários de campo, utilizados como ferramenta de sistematização dos dados para sua posterior análise. Os diários são compostos pela transcrição das falas dos apresentadores, repórter e entrevistados. Para análise dos testemunhos da audiência, foram observados os comentários feitos no Globoplay, plataforma da emissora em que era possível a participação do público com comentários sobre as reportagens.

\section{O testemunho dos jornalistas}

Intitulada Quem Sou Eu?, as reportagens foram veiculadas no Fantástico nos dias 12, 19 e 26 de março e 2 de abril de 2017. Com 12 minutos de duração em média, cada edição contou histórias de pessoas transgêneras. Para constituição desses relatos, deve ser levado em consideração o trabalho dos profissionais envolvidos para realização da série. Os testemunhos dos jornalistas podem, então, ser avaliados a partir dos âncoras e editores do programa e também da equipe de reportagem.

Os apresentadores Tadeu Schmidt e Poliana Abritta dividem a bancada do programa dominical desde 2014. É interessante destacar que o trabalho de criação dos textos que serão lidos por eles também exige o testemunho dos editores, que precisam assistir ao material desenvolvido pelos repórteres para decidir o que vai ser dito por quem está no estúdio da emissora.

Em Quem Sou Eu? percebe-se na composição dos discursos utilizados por Tadeu e Poliana um esforço por explicar a transgeneridade e apresentar o caminho seguido pelas pessoas transexuais para serem o que realmente são. $\mathrm{Na}$ terceira reportagem, por exemplo, eles dizem:

Poliana: Nos últimos dois domingos, nós mostramos aqui como é difícil nascer com um corpo de mulher e pensar como um homem ou o contrário se sentir mulher e ver um homem quando se olha no espelho.

Tadeu: Uma angústia que se manifesta já na infância, mas é só na vida adulta que os transgêneros podem dar o passo definitivo no processo de transição: a intervenção cirúrgica.

Poliana: Uma decisão difícil para essas pessoas que desde muito cedo sofrem com a rejeição (REDE GLOBO, 2017).

Observa-se como o tema foi tratado sob a perspectiva de mostrar que não é fácil ser uma pessoa transexual. O discurso deles revela como é difícil cada decisão tomada pelas pessoas que não se identificam com o gênero ao qual foram designados ao nascerem. No discurso de Poliana, observa-se a referência ao espelho porque toda a série é contada a partir de Alice, do livro de Lewis Carroll, e o objeto é um elemento importante na história.

Alice no País das Maravilhas ajuda a compor o testemunho de outra figura importante do ponto de vista de elaboração do texto televisivo: a equipe de reportagem. Renata Ceribelli traça, no seu texto, paralelos entre a história da protagonista do livro e pessoas transexuais e o repórter cinematográfico Marconi Matos atua construindo a narrativa visual.

A análise do testemunho de Renata Ceribelli, diante do que foi contado a ela, revela que a reportagem é conduzida por um caminho que primeiro tenta explicar a transgeneridade. "Olhe no espelho. Olhe e imagine que o que você vê não é o que você é” (CERIBELLI, 2017a), diz a repórter na abertura de seu texto no primeiro 
episódio da série e na sequência complementa com uma espécie de glossário em que explica alguns termos.

A identidade de gênero é uma definição se é homem ou se é mulher, como ela se sente, se percebe, como ela se reconhece. Gênero só existem dois: o masculino e o feminino. Transgênero é uma pessoa que não se identifica com o gênero de nascença. Por exemplo, uma pessoa que nasce homem, mas não se sente no gênero masculino ou que nasce mulher e não se identifica com o gênero feminino (CERIBELLI, 2017a).

No site da série, também existe um glossário com os termos empregados na reportagem. Constam termos e definições como transgênero, intersex e outras expressões. Aqui percebe-se, no entanto, que a reportagem é pautada pelo binarismo de gênero.

As conceituações sobre gênero surgiram, especialmente, a partir da década de 1960 do século passado com o avanço do movimento feminista. A perspectiva era a defesa de que o gênero correspondia ao sexo com o qual se vem ao mundo. E aqui o programa parece fazer uma correspondência direta entre gênero e sexo. Simone de Beauvoir, na década de 1940, já contestava esse modelo. A autora é mundialmente conhecida pela frase: "não se nasce mulher, torna-se mulher". Com esse texto, existe uma quebra na compreensão de gênero a partir do sexo.

Um olhar sobre os movimentos sociais na atualidade revela que existe uma diferenciação entre sexo e gênero, mas ainda muito vinculada à perspectiva biológica e natural. Persiste a ideia do sexo biológico ligado às informações que depreendemos de um corpo físico. A cartilha sobre diversidade sexual do Governo de São Paulo (DIVERSIDADE, 2018), por exemplo, e o Manual de comunicação LGBTI+ (REIS, 2018) incluem uma gama de informações que poderiam ser responsáveis por se classificar um corpo como "macho" ou "fêmea", ao definir o sexo biológico como características biológicas que a pessoa tem ao nascer. Os dois textos, entretanto, apesar de apontarem o sexo biológico como sendo algo imutável, consideram a identidade de gênero uma produção cultural e que excede a compreensão de masculino e feminino exclusivamente.

A negação ao binarismo de gênero está presente na pesquisa de Butler (2016), que aponta a performatividade do gênero. Segundo a filósofa, sexo/gênero devem ser compreendidos a partir de uma perspectiva não natural, mas cultural. E aponta como a heterossexualidade obrigatória e reprodutora materializou nos corpos modos de ser masculinos e femininos, mas chama atenção para as possibilidades de subversão a esse modelo. São as descontinuidades e dissonâncias em relação a sexo, gênero e desejo, como no caso da transgeneridade.

Consideram-se cisgêneras as pessoas que se definem como homens ou mulheres e se identificam com o gênero que foram designados ao nascer, a partir de critérios biológicos. A transgeneridade está associada a pessoas cuja identidade de gênero é diferente daquela atribuída quando bebê e compreende transexuais e travestis. Benevides e Nogueira (2019) consideram mulheres transexuais "pessoas que foram identificadas como sendo pertencentes ao gênero masculino no nascimento, mas que se reconhecem como pertencentes ao gênero feminino e se reivindicam como mulheres" (p. 11). E as travestis são pessoas que, ao nascerem, foram identificadas como do gênero masculino, mas que se identificam e se expressam como do gênero feminino. A diferença em relação às pessoas transexuais é que as travestis não se reivindicam como mulheres "da forma com que o ser mulher está construído em nossa sociedade" (p. 11).

As pessoas transexuais podem ainda ser binárias ou não-binárias. As binárias se reconhecem como homens ou mulheres e as não-binárias não se limitam às definições de masculino ou feminino.

Ao dizer que só existem dois gêneros, o masculino e o feminino, Quem Sou Eu? reproduz um modelo que vem sendo contestado, como foi visto, há um bom tempo. 
As explicações sobre gênero e sexualidade de Renata deveriam se aprofundar nas variações de gênero, mas a reportagem só entrevista pessoas transexuais binárias.

Ao contar as histórias a partir do testemunho enquanto repórter, sobressaem-se alguns discursos no texto de Renata Ceribelli. Além da falta de identificação entre corpo e como a pessoa se vê, destacam-se: a decisão de enfrentar quem a pessoa é e lutar por esse direito; o processo de redesignação sexual; a importância da aceitação; os direitos das pessoas transexuais; violência contra pessoas transexuais; a busca pela realização de sonhos e os relacionamentos amorosos para pessoas transgêneras. Essas são as estratégias discursivas empregadas pela repórter a partir de seu próprio testemunho diante do fato e também dos depoimentos de seus entrevistados. São esses enunciados que geram os processos de subjetivação.

Quando se depara com a história de Mel, uma garota de 11 anos que é transexual, Renata Ceribelli (2017a) diz:

Imagine ter 11 anos, apenas 11 anos e ter que tomar uma decisão como a de Alice. Ela está diante de várias portas e tem que passar pela menor delas, a mais difícil. As portas significam os mais difíceis caminhos que uma pessoa pode seguir.

A repórter apresenta, nesse momento do texto, a dificuldade que é para uma criança tomar conhecimento de que é uma pessoa transexual e que, para ser quem de fato é, terá que seguir um caminho difícil. As pessoas transexuais, assim como Alice, precisam passar por uma pequena porta. Esse desafio faz referência ao percurso árduo que é se reconhecer transexual diante do modelo da heteronormatividade e empreender as mudanças necessárias para se transformar na pessoa que se quer.

Esse processo passa, muitas vezes, especialmente no caso de pessoas transexuais binárias pela redesignação do corpo, que pode ser feita com o uso de hormônios e também com cirurgias. Nesse ponto, Ceribelli mostra o processo de hormonização de seus entrevistados como sendo um dos caminhos para que uma pessoa transexual avance em sua decisão. É uma das portas estreitas que a Alice parafrástica passa. Essa Alice ganha vida com as histórias de Bernardo e Andrea no segundo episódio da série. Bernardo se prepara para iniciar o tratamento hormonal e Andrea já faz.

Neste ano, Bernardo mudou de escola. Hoje é seu primeiro dia de aula e ele vai chegar se apresentando como um menino. Seus novos amigos vão aceitá-lo como um menino? Só o tempo dirá, mas ele vai continuar com o apoio da pessoa mais importante (CERIBELLI, 2017b).

A referência na passagem anterior se dá ao novo momento na vida do adolescente que passou por momentos muito difíceis na puberdade ao ver seu corpo crescer de uma forma que ele não se identificava. Somente agora com a hormonização, poderá completar sua transição. A jornalista também se refere ao apoio da mãe do jovem.

A questão da aceitação é outro tema bastante forte diante dos eventos testemunhados por Ceribelli. "O processo não é simples, causa sofrimento para criança e para família” (CERIBELLI, 2017a). Assim, a repórter mostra relatos de pessoas transexuais que receberam apoio familiar, como no caso apresentado, mas também de quem não recebeu. “Thaís é de Santa Maria da Vitória, na Bahia. Durante algum tempo, achou que ninguém poderia conhecê-la de verdade, nem mesmo a família" (CERIBELLI, 2017b). Renata, a partir do depoimento de Thaís, pergunta se ela sente saudade da família e como resposta ouve que teria sido mais fácil se tivesse recebido suporte dentro de casa.

Também, a partir da discussão sobre aceitação, ganham destaque dois outros testemunhos da repórter: a garantia e a violação de direitos. Na promoção de direitos, o foco do programa está nos serviços oferecidos pelo Sistema Único de 
Saúde (SUS) para as pessoas transexuais, incluindo os atendimentos psicológicos e os procedimentos de redesignação. "É possível fazer esse tratamento pelo SUS em nove centros pelo Brasil, mas é preciso ter mais de 18 anos e passar por acompanhamento psicológico" (CERIBELLI, 2017b). Ainda sob este viés, Renata fala sobre os riscos da automedicação de hormônios e, em uma associação com o chá do Chapeleiro Maluco de Alice, coloca uma de suas entrevistadas, Andrea, em uma mesa para também tirar dúvidas, mas com especialistas.

As principais dicas estão relacionadas à ideia de não tomar hormônios sem acompanhamento médico e a sempre utilizar a quantidade prescrita pelos médicos. Sobre os procedimentos cirúrgicos, ela ressalta: "Para fazer qualquer uma dessas operações pelo SUS, é preciso ser maior de 21 anos e ter passado por dois anos de acompanhamento médico e psicológico e a cirurgia mais complexa com certeza é a do órgão sexual" (CERIBELLI, 2017b). Daí, passa a acompanhar Luisa, que fará uma cirurgia para readequação do pomo de adão.

A violação de direitos é tematizada a partir da violência a que pessoas transexuais estão submetidas. Thaís conta para Renata que já apanhou por ser uma pessoa transexual. Voltando aos paralelos entre o texto de Lewis Carroll, a reportagem associa a Rainha de Copas aos algozes das pessoas transexuais.

Renata: O caminho de Thaís é tão perigoso quanto o de Alice quando deu de cara com a Rainha de Copas. No reino da Rainha de Copas, todas as rosas têm que ser vermelhas. Mesmo as que nasceram brancas têm que ser vermelhas e, diante de quem a contraria, ela ordena: Rainha de Copas (animação): Cortem-lhe a cabeça.

Renata: A expectativa de vida das pessoas trans no Brasil não passa de 35 anos.

Rainha de Copas (animação): Cortem-lhe a cabeça.

Renata: Em 2016, 177 trans foram mortos no país.

Rainha de Copas (animação): Cortem-lhe a cabeça.

Renata: Desde o começo deste ano, já foram 33 assassinatos.

Rainha de Copas (animação): Cortem-lhe a cabeça.

Renata: Em nenhum outro lugar do mundo, os trans são vítimas de tanta violência.

Rainha de Copas (animação): Cortem-lhe a cabeça, cortem-lhe a cabeça, cortem-lhe a cabeça (CERIBELLI, 2017c).

A repórter emprega o conhecido bordão da personagem de Alice para associar às mortes de pessoas transexuais no Brasil. Os dados são revelados um a um enquanto a Rainha surge ordenando a morte. A reportagem traz uma reflexão urgente sobre transfobia a partir desses enunciados.

Outros dois testemunhos acompanhados pela jornalista que servem para composição de seu texto são a busca pela realização de sonhos e os relacionamentos amorosos para pessoas transexuais. Após falar sobre as violências pelas quais Thaís passa, Renata diz:

Mesmo assim, Thaís segue sonhando. Sonha um dia se tornar publicitária como a Manoela, que está desempregada, mas sonha em ser produtora cultural. Ou a Dandara que sonha em ser atriz e hoje é assistente administrativa. Gustavo é gerente de loja e sonha em ser professor de Educação Física. A Renata é recepcionista e sonha em ser cantora. O Roger é stripper e sonha em ser administrador. A Rafaela é prostituta e sonha em ser coreógrafa. Já a Luisa quer ser engenheira e está conseguindo estudar para isso, mas o caminho que a trouxe até aqui não foi fácil (CERIBELLI, 2017c).

É interessante esse momento em que a reportagem fala sobre os sonhos das pessoas transexuais. Os desejos foram ligados à vida profissional, mas contribuem para diversificar as possibilidades de emprego para esse grupo social. Sabe-se que, majoritariamente, pessoas transexuais atuam na prostituição. Sem demérito algum, a reportagem aponta outras atividades como também possíveis.

A história de Alice volta à reportagem quando a jornalista quer mostrar pessoas transexuais mais seguras de quem são e de seus desejos. Para isso, ela se reme- 
te ao julgamento de Alice pela Rainha de Copas e revela que, agora, será mais fácil pela segurança que se conquista com apoio de familiares e amigos.

O testemunho sobre os relacionamentos amorosos revela a dificuldade de Alessandra em se relacionar. Para falar sobre isso, associa novamente ao livro de Lewis Carroll destacando quando Alice desperta para realidade e percebe que tudo não passou de um sonho. "Leka despertou para realidade e percebeu que tudo seria bem parecido com o que ela já tinha vivido até então" (CERIBELLI, 2017d). Nesse momento, a entrevistada fala sobre o preconceito que continuou sofrendo e a dificuldade em se relacionar.

O final da reportagem acompanha um casal de pessoas transexuais que tiveram um filho. Anderson e Helena são os pais de Gregório.

Gregório vai aprender desde cedo que as pessoas são diferentes em tudo, afinal, a árvore da diversidade, que mostramos no início da nossa série, é realmente cheia de ramificações, mas quando falamos de amor não existe diferença (CERIBELLI, 2017d).

Ela conclui o testemunho da reportagem ressaltando uma geração que pode lidar com a questão da transgeneridade a partir de outros pontos de vista, mais voltados para respeito e valorização das diferenças.

\section{O testemunho das fontes}

Outra dimensão testemunhal que está presente nas narrativas jornalísticas é o testemunho das fontes, das pessoas que são entrevistadas para realização da matéria. A análise da série Quem Sou Eu? revela que os testemunhos da repórter são alimentados pelos discursos de quem foi consultado por presenciar algum fato ou viver determinada situação. Os testemunhos das fontes são correspondentes aos tópicos discursivos apresentados nos testemunhos da repórter em um claro movimento de influência que a escuta das fontes tem na composição do texto da jornalista. São eles: explicações sobre o que é a transgeneridade; a decisão de enfrentar quem a pessoa é e lutar por esse direito; o processo de redesignação sexual; a importância da aceitação; os direitos das pessoas transexuais; violência contra pessoas transexuais; a busca pela realização de sonhos e os relacionamentos amorosos para pessoas transgêneras.

Como dito anteriormente, os entrevistados da série são formados por especialistas, familiares, amigos e pessoas transexuais. Os testemunhos dos especialistas aparecem para explicar o que é a transgeneridade e para falar sobre os direitos das pessoas transexuais em relação aos processos de redesignação do corpo.

Numa entrevista com o psiquiatra Alexandre Saadeh, coordenador do Ambulatório Transdisciplinar de Identidade de Gênero e Orientação Sexual do Instituto de Psiquiatria do Hospital das Clínicas da Faculdade de Medicina da Universidade de São Paulo, há uma explicação científica para a transexualidade.

No embrião humano, a genitália se forma por volta da décima semana. Enquanto isso, o cérebro está em desenvolvimento. Por volta da vigésima semana, se define a área que dá a identidade de gênero. Genitália masculina, cérebro masculino, genitália feminina com o cérebro feminino ou o contrário: genitália é masculina, mas o cérebro se estruturou como feminino ou a genitália feminina com o cérebro masculino. E aí a gente tem o caso de uma criança que vai nascer transgênera (SAADEH, 2017).

Observa-se um apelo ao discurso biológico para compreensão da questão da transgeneridade. Não há, na fala do médico, uma explicação que aponte para a possibilidade de sexo e gênero serem construções culturais. Essa visão científica na determinação de gênero e sexualidade é, inclusive, bastante questionada. Vergueiro (2015), por exemplo, discute como o discurso da ciência cria as categorias 
de homem, mulher, travesti, transexual. Saadeh também aparece para falar sobre o tratamento na infância. Esclarece que há um bloqueio nos hormônios durante a puberdade e que o tratamento só pode ser feito a partir dos 16 anos. Alexandre também é acionado pela reportagem para falar sobre as cirurgias no SUS e revela que a saúde pública não consegue dar conta da quantidade de pedidos que existem, por isso existe uma fila de espera.

A endocrinologista Karen Seidel (Instituto Estadual de Diabetes e Endocrinologia do Rio de Janeiro) explica a Andrea, no segundo episódio, diante das dúvidas sobre o tratamento hormonal, que o corpo estará, em dois anos, com as características do corpo feminino. O urologista Eloisio Alexsandro do Hospital Universitário Pedro Ernesto da Universidade do Estado do Rio de Janeiro - (Hupe/ UERJ) explica que a demanda pela cirurgia de redesignação sexual é muito maior que a capacidade de resolução. A reportagem acaba denunciando a realidade que as pessoas transexuais enfrentam no SUS. Os longos períodos de espera até conseguir a autorização para realização do procedimento.

Sob a perspectiva dos não especialistas, os testemunhos das pessoas transexuais que aparecem na reportagem revelam os desafios da transgeneridade para essas pessoas e também a luta pelo direito de serem quem são. Cristina, na abertura da série diz:

Por mais que não esteja nos meus registros, hoje, eu não aceito que me tratem por um nome diferente de Cristina. Hoje, o meu corpo me representa. É como se eu tivesse passado a vida inteira dentro de um quarto e, há um ano, eu tenha me libertado de tudo isso para ser realmente quem eu sou. Tem dias que eu acho que as pessoas só conseguiriam me entender se elas fossem quem eu sou ou se pelo menos elas me deixassem ser (CRISTINA, 2017).

Ela também compartilha que, desde criança, já sabia que era uma mulher, mas que as pessoas não a viam assim. Cristina também contribui para o avanço da discussão sobre gênero quando afirma: "Eu quero operar, mas não é uma cirurgia que vai me tornar mais mulher. Eu já sou mulher" (CRISTINA, 2017). A perspectiva dela se aproxima das teorias, que, como vimos, não estabelecem uma ordem natural entre sexo e gênero. Há também uma subversão ao modelo heteronormativo nos termos de Butler (2016), quando vislumbra a existência de mulher com genitália masculina no caso da entrevistada.

Um recurso empregado na reportagem é de trazer testemunhos de familiares e amigos. A mãe de Bernardo, no segundo episódio, mostra total apoio às decisões do filho. "Ele um dia chegou e disse: 'mãe, vamos comprar um brinco porque eu prometi para psicóloga que eu ia usar brinco'. Entendi que não era isso que eu queria. Eu não estava levando o Bernardo para se curar de alguma coisa" (LUCIANA, 2017).

Foi a partir desse episódio que ela resolveu apoiar as mudanças que o filho queria fazer. Os pais de Luisa, cuja história é contada no terceiro episódio, por exemplo, bancam a cirurgia para verem a filha feliz.

Porém, sensível às lutas enfrentadas pelas pessoas transexuais, a série também destaca a situação de pessoas que não receberam esse apoio e que se tornaram muito mais vulneráveis para situações de violência. Foi o caso de Thaís. "Na rua, a gente está sujeita a tudo, não é, Renata? Qualquer tipo de violência, de discriminação, preconceito, agressão, pessoas maldosas" (THAÍS, 2017).

A realização de sonhos também são testemunhos compartilhados em Quem Sou Eu?. A reportagem associa essa conquista especialmente aos procedimentos de redesignação que são realizados. Dante é entrevistado depois de ter feito a mastectomia, cirurgia para retirada das mamas. "Essa é a visão que eu sempre quis ver daqui de cima depois de tirar a faixa que cobria a cirurgia de retirada dos seios" (DANTE, 2017). Ele fala exibindo o tórax depois do procedimento. Luisa diz que sempre teve outros sonhos. "A cirurgia é uma forma de aumentar a minha quali- 
dade de vida. Eu me sentia como uma pessoa deficiente mesmo. É realmente um divisor de águas na minha vida" (LUISA, 2017).

No último episódio, Renata colhe um testemunho de uma mulher transexual que realizou os procedimentos que quis, mas sente ainda o preconceito ao redor. Alessandra, também chamada de Leka, revela as dificuldades para namorar. "Nunca. Antes, também não. Nunca namorei na vida. [...] Eu tenho medo de me entregar à pessoa e a pessoa me decepcionar. De ele descobrir que é trans e falar: 'eu não quero'. Isso já aconteceu” (ALESSANDRA, 2017).

No encerramento da série, no entanto, é contada a história de uma casal de pessoas trans que, na época de realização da reportagem, haviam tido um filho, sonho compartilhado com outro casal que é mostrado também no Quem Sou Eu? É uma forma de mostrar que o amor é possível para pessoas transgêneras.

\section{O testemunho dos consumidores}

O último aspecto do testemunho abordado neste trabalho diz respeito ao testemunho dos consumidores das notícias. A partir dos testemunhos exibidos na série de reportagem, a audiência é submetida a modos de ver e entender a questão da transgeneridade.

O jornalismo opera como um dispositivo que pode ser compreendido como responsável por governar as atividades da população, determinar a conduta das pessoas (FOUCAULT, 2001). Deleuze (1990) considera que o dispositivo está alicerçado em três grandes eixos: saber, poder e subjetivação. O filósofo afirma que os dispositivos atuam como máquinas de fazer ver e fazer falar. A partir desse pensador, a ideia de dispositivo aproxima-se da noção de modos de existência porque o dispositivo estabelece formas de viver.

É o caso do jornalismo que atua regendo seu público e promovendo processos de subjetivação. Entende-se que as subjetivações relacionadas a gênero e sexualidade foram produzidas por Quem Sou Eu? a partir dos testemunhos da equipe da emissora e dos entrevistados diante da transgeneridade.

Assim, é possível apontar que a reportagem contribui para formação de testemunhos por parte da audiência das seguintes ordens: compreensão de que a transgeneridade não é uma escolha, mas algo biológico; conhecimento das dificuldades pelas quais uma pessoa trans para se reconhecer como tal e encarar o preconceito da sociedade; entendimento sobre o processo de redesignação sexual, sensibilização para a questão do apoio familiar, informações sobre os direitos das pessoas trans, atenção para a violência a que as pessoas transexuais estão submetidas, realidade e sonhos na vida de uma pessoa transexual e como elas se relacionam.

Essas subjetivações surgem, obviamente, seguindo os testemunhos da repórter e os que ela colhe com as fontes e utiliza na reportagem. É importante destacar também que esses modos de ver e entender a realidade engendrados a partir da reportagem se dão a partir das estratégias discursivas que foram empregadas. Sendo assim, observa-se que a reportagem estabelece uma visão para a audiência de que a transgeneridade existe a partir de um fenômeno biológico, embora haja outras visões, como citadas anteriormente, que poderiam ter sido discutidas. Ela também leva para o telespectador o sofrimento que as pessoas transexuais passam com a intenção clara de contribuir para que o público respeite as pessoas e as diferenças. Ao mostrar o processo de redesignação dos corpos, o Fantástico se dirige a pessoas que vão passar pelo procedimento, destacando a importância de seguir orientações médicas e nunca se automedicar, mas também sugere a luta que é conseguir fazer os procedimentos e como essas conquistas alteram a vida das pessoas transexuais, contribuindo para empatia por parte de quem assiste à reportagem.

Quando mostra pessoas transexuais falando sobre o apoio da família e parentes demonstrando respeito diante das decisões dos filhos, o programa chama 
a atenção do público para a importância desse acolhimento e sensibiliza pais, que passam por isso, a encarar o desafio de estar ao lado dos filhos. Ao falar sobre direitos das pessoas transexuais de atendimento no SUS, o olhar se volta mais uma vez para outras pessoas que também não se identificam com o gênero ao qual foram designadas quando nasceram. A repórter mostra o que o SUS oferece e o que é necessário para conseguir atendimento.

Ao discutir violência contra pessoas transgêneras, Quem Sou Eu? foge do discurso comum em notícias policiais em que pessoas transexuais são responsáveis pelos crimes. A série revela dados alarmantes de violência e estimula uma reflexão sobre a gravidade dos números na tentativa de contribuir para que avance o respeito e diminua a agressão contra esse grupo social.

Também chama atenção a repórter ter abordado a questão sob o ponto de vista dos sonhos e dos relacionamentos amorosos porque contribui para que se consiga construir a narrativa a partir dos afetos e não do esdrúxulo, excêntrico, comum em outras reportagens.

O testemunho dos consumidores da notícia foi observado no Globoplay, plataforma streaming da Rede Globo, em que é possível assistir aos programas já exibidos na emissora, incluindo a série. A emissora não abriu a seção de comentários no site especial da série. Como foi dito anteriormente, priorizou-se, nesta análise, os canais próprios da Globo. Os comentários foram lidos e selecionados de acordo com a pertinência ao estudo realizado. Existem, então, comentários contrários ao tema abordado, considerando-o irrelevante ou absurdo, mas há também testemunhos como o de uma usuária que diz: "Parabéns a Rentana [sic] e todos responsáveis pela reportagem! Muito boa a iniciativa, já que até pouco tempo atrás era algo nunca dito! É algo que existe, que acontece, e nada mais natural ser esclarecido!" (GLOBOPLAY, 2017). Outro usuário escreve: "Muito boa a reportagem, bem didática para quem realmente que ir além dos preconceito e entender melhor o assunto" (GLOBOPLAY, 2017).

No entanto, diante do tema, há comentários como o de um usuário que sugere: "quando a mulher vai para trabalhar os filhos se tornam complexados e entram em crise de sexualidade. Não existia transgêneros quando o homem trabalhava e a mulher cuidava da mulher. Simples assim" (GLOBOPLAY, 2017). Outro diz que "XX nunca vai ser XY e XY nunca vai ser XX".

As pessoas que reclamam acompanham o discurso já em circulação de doutrinação de crianças para que sejam transexuais e de que a Globo é uma emissora ruim. Veiculada antes das eleições de 2018, a série se deparou com uma sociedade bastante polarizada e é possível perceber isso na observação de alguns comentários dos vídeos, como os mostrados anteriormente.

\section{Considerações Finais}

Este trabalho se propôs a compreender, a partir de uma série especial televisiva, como o caráter testemunhal do jornalismo opera a partir de três dimensões, incluindo a instância produtora, os entrevistados e os consumidores. A ideia foi evidenciar como os testemunhos em reportagens estabelecem processos de subjetivação.

Foi escolhida, como material de investigação para esta pesquisa, a série, exibida no Fantástico, Quem Sou Eu?. A partir da análise, percebeu-se que os testemunhos da equipe de reportagem, das fontes ouvidas e também da audiência pertencem às mesmas ordens discursivas, com exceção do testemunho de parte da audiência que não aceita o tratamento dado pela jornalista e pelos entrevistados ao tema. Isso se evidencia porque ao ouvir as histórias que deverão ser contadas, a equipe de reportagem cria os discursos que deverão gerar na sociedade processos de subjetivação. 
O testemunho da repórter da série é possível graças à aprovação do tema na emissora. Reconhecidamente, o telejornalismo agenda os assuntos que serão debatidos pelas pessoas. Ao decidir abordar a transgeneridade sob uma perspectiva não usual em emissoras de TV, o Fantástico contribuiu para novos olhares sobre pessoas transexuais. Esse movimento acompanha a responsabilidade social trabalhada na empresa diante das leis de mercado. A decisão de pautar a temática não é por acaso, mas está alinhada a um discurso mais progressista que é empregado por marcas que querem ser vistas pelo mercado como adaptadas à globalização.

No entanto, o mesmo programa da Rede Globo, em 3 de fevereiro de 2019, divulgou uma reportagem sobre a morte de Lourival Bezerra de Sá, morador de Campo Grande, na qual não tratou uma pessoa transexual com dignidade e reconhecimento de direitos. O segredo de Lourival, forma como foi chamada pelos apresentadores, contou a história de um homem transexual que faleceu em outubro de 2018, vítima de um infarto fulminante, e que teve sua identidade contestada após a morte. De acordo com as pessoas ouvidas na reportagem, amigos e filhos não sabiam que ele era uma pessoa transexual. $O$ texto não trata Lourival como deveria e a repórter, apesar de se referir ao personagem no pronome masculino, vacila quando questiona: "Como Lourival, que era mulher, pôde se passar por homem por tanto tempo?”.

Considera-se que, apesar das novas subjetividades possíveis a partir do conteúdo veiculado no especial, a questão ainda foi discutida muito sob a perspectiva biológica, sem levar em consideração a cultura em Quem Sou Eu? Também é importante destacar que, apesar de contribuir com uma série sobre a temática, faltou ao programa jornalístico um tratamento adequado na reportagem de 2019. Sexo e gênero são temáticas importantes para serem desbravadas pelo jornalismo, que pode ampliar as possibilidades de entendimento.

É papel do dispositivo telejornalismo atuar como um meio capaz de criar novas percepções sociais sobre assuntos relevantes para grupos sociais marginalizados socialmente e com pouco espaço nos meios de comunicação. A expectativa é que a análise presente neste trabalho contribua para que outras reportagens e pesquisas formem novos olhares testemunhais sobre a transgeneridade, assegurando direitos e garantindo respeito e valorização das humanidades.

\section{Referências}

ALESSANDRA. In: Fantástico [Quem Sou Eu?]. Rio de Janeiro: Rede Globo, 2 abr. 2017. Programa de TV.

BARCELLOS, Caco. In: Profissão Repórter [Transgêneros]. Rio de Janeiro: Rede Globo, 22 jun. 2014. Programa de TV.

BENEVIDES, Bruna G.; NOGUEIRA, Sayonara Naider Bonfim. Dossiê: assassinatos e violência contra travestis e transexuai no brasil em 2018. São Paulo: Associação Nacional de Travestis e Transexuais Do Brasil (Antra); Instituto Brasileiro Trans de Educação (IBTE), 2019. Disponível em: https://antrabrasil.files.wordpress. com/2019/01/dossie-dos-assassinatos-e-violencia-contra-pessoas-trans-em-2018. pdf. Acesso em: 4 mai. 2020.

BUTLER, Judith. Problemas de Gênero: feminismo e subversão da identidade. 10. ed. Rio de Janeiro: Civilização Brasileira, 2016.

CERIBELLI, Renata. In: Fantástico [Quem Sou Eu?]. Rio de Janeiro: Rede Globo, 12 mar. 2017a. Programa de TV. 
CERIBELLI, Renata. In: Fantástico [Quem Sou Eu?]. Rio de Janeiro: Rede Globo, 19 mar. 2017b. Programa de TV.

CERIBELLI, Renata. In: Fantástico [Quem Sou Eu?]. Rio de Janeiro: Rede Globo, 26 mar. 2017c. Programa de TV.

CERIBELLI, Renata. In: Fantástico [Quem Sou Eu?]. Rio de Janeiro: Rede Globo, 2 abr. 2017d. Programa de TV.

CRISTINA. In: Fantástico [Quem Sou Eu?]. Rio de Janeiro: Rede Globo, 12 mar. 2017. Programa de TV.

DANTE. In: Fantástico [Quem Sou Eu?]. Rio de Janeiro: Rede Globo, 26 mar. 2017. Programa de TV.

DELEUZE, Gilles. ¿Que és un dispositivo? In: DELEUZE, Gilles. Michel Foucault, filósofo. Barcelona: Gedisa, 1990. p. 155-161.

DIVERSIDADE sexual e cidadania LGBT. Coordenação de Políticas para a Diversidade Sexual. $3^{\text {a }}$ ed. São Paulo: SJDC/SP, 2018.

FOUCAULT, Michel. Microfísica do Poder. 16. ed. Rio de Janeiro: Graal, 2001.

FROSH, Paul; PINCHEVSKY, Amit. Media witnessing: Testimony in the age of mass communication. Londres: Paugrave Macmillan, 2009.

FANTÁSTICO. GLOBOPLAY. Disponível em: globoplay.globo.com. Acesso em: 10 jun. 2020.

HARTMANN, Jeniffer Morel. Identidades trans em pauta: Representações sociais de transexuais e travestis no telejornalismo policial brasileiro contemporâneo. $70 \mathrm{f}$. Monografia (Curso de Jornalismo) - Universidade Federal de Santa Catarina, Florianópolis, 2014. Disponível em: https://core.ac.uk/download/pdf/30402937.pdf. Acesso em: 6 mai. 2020.

LUCIANA. In: Fantástico [Quem Sou Eu?]. Rio de Janeiro: Rede Globo, 19 mar. 2017. Programa de TV.

LUCIANO. In: Profissão Repórter [Transgêneros]. Rio de Janeiro: Rede Globo, 22 jun. 2014. Programa de TV.

LUISA. In: Fantástico [Quem Sou Eu?]. Rio de Janeiro: Rede Globo, 26 mar. 2017. Programa de TV.

MEL. In: Fantástico [Quem Sou Eu?]. Rio de Janeiro: Rede Globo, 12 mar. 2017. Programa de TV.

MÍDIA DADOS BRASIL, 2018. 50 anos Grupo de Mídia São Paulo. São Paulo: Grupo de Porto Palavra, 2018.

PÂMELA. In: Profissão Repórter [Transgêneros]. Rio de Janeiro: Rede Globo, 22 jun. 2014. Programa de TV. 
OLIVEIRA, Ana Beatriz Caldas. Viver e morrer travesti no jornalismo policial: uma análise da desconstrução da identidade trans em portais paraibanos. $104 \mathrm{f}$. Dissertação (Mestrado em Comunicação e Culturas Midiáticas) - Universidade Federal da Paraíba, João Pessoa, 2018. Disponível em: https://repositorio.ufpb.br/ jspui/bitstream/123456789/15012/1/Arquivototal.pdf. Acesso em: 8 mai. 2020.

REDE GLOBO. Fantástico. Disponível em: http://especiais.g1.globo.com/fantastico/2017/quem-sou-eu/. Acesso em: 10 jun. 2020.

REIS, Toni (org.). Manual de comunicação LGBTI+. Curitiba: Aliança Nacional LGBTI/Gay Latino, 2018. Disponível em https://unaids.org.br/wp-content/uploads/2018/05/manual-comunicacao-LGBTI.pdf. Acesso em: 26 abr. 2020.

ROCHA, Maria Eduarda da Mota. A nova retórica do capital: a publicidade em tempos neoliberais. São Paulo: Editora da Universidade de São Paulo, 2010.

SAADEH, Alexandre. In: Fantástico [Quem Sou Eu?]. Rio de Janeiro: Rede Globo, 12 mar. 2017. Programa de TV.

THAÍS. In: Fantástico [Quem Sou Eu?]. Rio de Janeiro: Rede Globo, 26 mar. 2017. Programa de TV.

VERGUEIRO, Viviane. Por inflexões decoloniais de corpos e identidades de gênero inconformes: uma análise autoetnográfica da cisgeneridade como normatividade. 244 f. Dissertação (Mestrado em Cultura e Sociedade) - Universidade Federal da Bahia, Salvador, 2015. Disponível em: https://repositorio.ufba.br/ri/bitstream/ri/19685/1/VERGUEIRO\%20Viviane\%20-\%20Por\%20inflexoes\%20decoloniais $\% 20 \mathrm{de} \% 20$ corpos\%20e\%20identidades\%20de\%20genero\%20inconformes. pdf. Acesso em: 28 jan. 2021. 